\title{
Antennal sensilla of cleptoparasitic and non-parasitic bees in two subfamilies of Apidae
}

\author{
Gerónimo Luis GALVANI ${ }^{1}$, Rocío Ana GonzÁlez-VAQUeRO ${ }^{1}$, \\ Carolina Guerra-NAVARro ${ }^{2}$, Beatriz Patricia SetTEMBrinI ${ }^{1,3}$

\begin{abstract}
${ }^{1}$ MACN-CONICET, Museo Argentino de Ciencias Naturales "Bernardino Rivadavia", Ángel Gallardo 470, C1405DJR, Ciudad de Buenos Aires, Argentina

${ }^{2}$ Facultad de Ciencias Exactas y Naturales, Universidad de Buenos Aires, Intendente Güiraldes 2160-Ciudad Universitaria, C1428EGA, Ciudad de Buenos Aires, Argentina

${ }^{3}$ IIMT-UA-CONICET, Facultad de Ciencias Biomédicas, Universidad Austral, Presidente Perón 1500, B1629AHJ, Pilar,
\end{abstract} \\ Buenos Aires, Argentina
}

Received 4 April 2016 - Revised 17 October 2016 - Accepted 25 November 2016

\begin{abstract}
In bees, most of the comparative studies linking the sensory system and behavior were performed in social species. Here, we describe the morphology of antennal sensilla in solitary and cleptoparasitic bees of Apinae and Nomadinae. The external and internal structure of sensilla and setae as well as their distribution in flagella were studied in detail in two different host-cleptoparasitic associations. In addition, taking into account the presence of pores, the distribution of sensilla was compared in females and males of 39 species of these subfamilies. It was found that males of non-parasitic bees showed a higher number of multiporous sensilla. Females had more uniporous and nonporous sensilla than males. Cleptoparasitic bees showed a low diversity in types of sensilla and no sexual dimorphism in number. The pattern of sensilla in males and their cleptoparasitic females was discussed in the context of their ecological roles.
\end{abstract}

antennal morphology / sensilla ultrastructure / olfaction / dimorphism

\section{INTRODUCTION}

Insect sensilla are the basic structural units for the detection of chemical, thermal, and mechanical signals from the external environment. The abundance of chemoreceptor structures in appendages such as antennae, mouth parts, and legs suggests the critical role of chemical stimuli in the construction of some reproductive and feeding behaviors. Within active flying insects, high abundance of antennal sensilla is a common pattern.

Electronic supplementary material The online version of this article (doi:10.1007/s 13592-016-0486-y) contains supplementary material, which is available to authorized users.

Corresponding author: B. Settembrini, settembrini@macn.gov.ar

Manuscript editor: Bernd Grünewald
This phenomenon may be correlated to the capacity of an individual to detect an odorant molecule and to orient towards the source of the chemical signal (Chapman 1982).

Regarding Hymenoptera, morphological and physiological investigations in ants showed that there is a strong correlation between the patterns of antennal sensilla and the tasks performed by the different castes of the colony (Sheridan 1996; Ozaki et al. 2005; Mysore et al. 2010). In sphecoid wasps, the arrangement of sensilla is known to be related to prey preference (Polidori et al. 2012).

Studies linking behavior and antennal sensilla were performed mainly in social bees. A strong correlation between the abundance of sensilla and the capacity to locate a food source for the colony has been reported in workers of Apis mellifera L. and Bombus terrestris (L.) (Spaethe et al. 2007; Riveros and Gronenberg 2010). Morphological 
studies on the antenna of $A$. mellifera drones and research about the processing and integration of olfactory signals have provided valuable information to understand the mechanism(s) for the detection of the queen pheromone (Sandoz et al. 2007). However, it should be noted that most of species are solitary and display different types of interand intraspecific behaviors from those reported for social bees.

A special type of behavior related to parental care is cleptoparasitism, where a cleptoparasitic female enters the nest of a host and lays an egg inside a cell. After eclosion, the cleptoparasitic larva feeds on the food stored for the host larva. During the evolutionary history of Apidae, cleptoparasitism arose in diverse tribes of Apinae and in the large subfamily Nomadinae (Michener 2007). Morphological evidence suggests that the antennal sensory system may have experienced different selection pressures during the evolution of cleptoparasitic and nonparasitic bees (Wcislo 1995). Although there are many solitary and cleptoparasitic tribes, little is known about the morphology and function of antennal sensilla in Apidae (Galvani et al. 2008). Some behavioral and physiological studies in parasitic females indicate the existence of a multisensory mechanism for the detection of hosts by the antennae (Cane 1983; Dötterl 2008). Nevertheless, the sensory mechanisms developed by cleptoparasitic bees remain still obscure. New data on antennal sensilla of solitary bees are needed to understand possible associations between the antennal system and the cleptoparasitic behavior.

In this study, we describe the morphology, distribution, and abundance of the main types of antennal sensilla in cleptoparasitic and non-parasitic bees of Apidae. We have chosen two cleptoparasite-host associations Leiopodus lacertinus Smith cleptoparasite of Melitoma segmentaria (Fabricius) and Doeringiella nobilis (Friese) cleptoparasite of Thygater analis (Lepeletier). Comparisons were performed in other cleptoparasitic and non-parasitic species from the subfamilies Nomadinae and Apinae. Our findings are discussed in relation to the specific behaviors of these species.

\section{MATERIAL AND METHODS}

\subsection{Specimens}

During the spring-summer period, the species M. segmentaria (Apinae: Emphorini), T. analis (Apinae: Eucerini), L. lacertinus (Apinae: Protepeolini), and D. nobilis (Nomadinae: Epeolini) were collected in the urban reserve "Reserva Ecológica Costanera Sur" (Buenos Aires, Argentina). Descriptions of antennal sensilla in $M$. segmentaria and D. nobilis have been already reported (Galvani et al. 2008, 2012). Here, they are only referred to serve as a comparison between groups if either ultrastructure or density is considered. Antennae from males and females belonging to 39 species of Apinae and Nomadinae (ESM: Table SI) were studied. These samples were obtained from insects stored in the División Entomología (Museo Argentino de Ciencias Naturales "Bernardino Rivadavia").

\subsection{Morphology and histology}

A detailed description of the protocol employed for scanning electron microscopy (SEM) and transmission EM (TEM) is provided as Electronic Supplementary Material (ESM: Morphology and histology). For SEM, antennae were processed according to Galvani et al. (2012). For TEM, antennae from live insects were processed following the protocol by Aguirre et al. (2013). Ultrathin sections mounted on formvar-coated copper grids were viewed with a Zeiss M10C electron microscope (Carl Zeiss Microscopy GmbH, Oberkochen, Germany).

\subsection{Determination of the number of sensilla}

The antenna of bees is formed by 10 flagellomeres in females and 11 in males, which are numbered consecutively F1 to F10/F11 from the pedicel to the tip of the organ (ESM: Figure S1A). Sensilla were identified according to Ågren (1977) and counted from serial SEM micrographs using Image J software (NIH, USA). Densities of sensilla were calculated by setting a rectangular area on the dorsal side of each 
flagellomere; this area was limited by the entire length of the segment (the $X$-axis), while the $Y$-axis was half the length of each flagellomere (Galvani et al. 2012). Those types of sensilla with less than four counts per flagellomere as well as pit organs were excluded from the study. To avoid possible deviation effects, the most proximal flagellomeres of females (F1) and males (F1-F2) bearing a very low number of sensilla were not included in the statistical analyses.

\subsection{Terminology}

The terminology proposed by Ågren (1977) was used to describe the morphology of flagellar sensilla. In order to confirm the functional sensory type (multi-, uni-, or nonporous sensilla), the internal structure of the subtypes of sensilla trichodea and setae was analyzed. Sensilla placodea and basiconica were described by taking into account only the external morphology (Galvani et al. 2012). To assign a functional role to each type, previous reports were considered (Slifer and Sekhon 1961; Whitehead and Larsen 1976).

\subsection{Statistical analyses}

The values of density in the types of sensilla were pooled on the basis of the presence of pores (multi-, uni-, or nonporous) together with their positions on the flagella (proximal: F2/3 to F5, medial: F6-9/10, and distal sensilla: F10/11). The intraspecific comparisons in density of sensilla for cleptoparasite-host associations in the specimens mentioned above ( $n=8$, see Section 2.1) were performed by ANOVA followed by post hoc Tukey's test to reveal the effects of a given position in the flagellum. For the comparisons of the different patterns of distribution in cleptoparasitic and non-parasitic bees of Apinae and Nomadinae, the densities of sensilla in 39 species $(n=3)$ from both sexes were pooled. The means were log transformed and the principal component analysis (PCA) was performed. All data were analyzed using the Infostat Software (FCA-UNC, Córdoba, Argentina).

\section{RESULTS}

\subsection{Morphology of antennal sensilla}

\subsubsection{Flagellar sensilla}

The classification proposed by Ågren (1977) recognizes two main categories: innervated sensilla and non-innervated setae. There are six types of sensilla: placodea, trichodea, basiconica, coeloconica, coelocapitular, and ampullacea (Figures 1a-d and 2a and ESM: Figure S1a-c). In all the species, sensilla were more abundant in the dorsal area of flagella (Figure 2a), whereas the ventral side showed spiniform setae (Figure $2 b$ ) and few sensilla trichodea. The sensillum placodeum ( $\mathrm{sPa}$, Figures $2 \mathrm{a}$ and $3 \mathrm{a}$ ) is a flattened ovoid disc with multiple pores on its surface (multiporous sensillum). These sensilla were always present on the dorsal surface of F2-F10/11.

The sensillum basiconicum ( $\mathrm{sBa}$ ), also called peg-like sensilla, was seen as straight hair with a blunt tip and a single pore which sometimes may be not visible (Figures 1c and 2a and ESM: Figures S1 and S2). The length and width of this type of sensillum varied within species, but the size of the insertion zone was always 1.5 times wider than the base.

\subsubsection{Setae}

In SEM observations, two types of setae were recognized (Figure 2a, b). The dorsal setae showed a foliate or saber-like morphology (Figure 2a) with similar width and length than that of sensilla trichodea. However, dorsal setae had an insertion site deeper than that of sensilla. Besides, it was observed that one face of the seta bends to the antennal cuticle (Figure 2a, c). TEM observations revealed the absence of soft tissues inside dorsal setae and around the base (Figure 2c). Some of these setae showed dark fibrillar material close to the base and inside the antenna. Spiniform setae were commonly found in the lateral and ventral sides all over the surface (Figure 2b). Ultrathin sections of spiniform setae showed no other tissue than cuticle (Figure 2d). In both types of setae, TEM revealed that they are formed only 

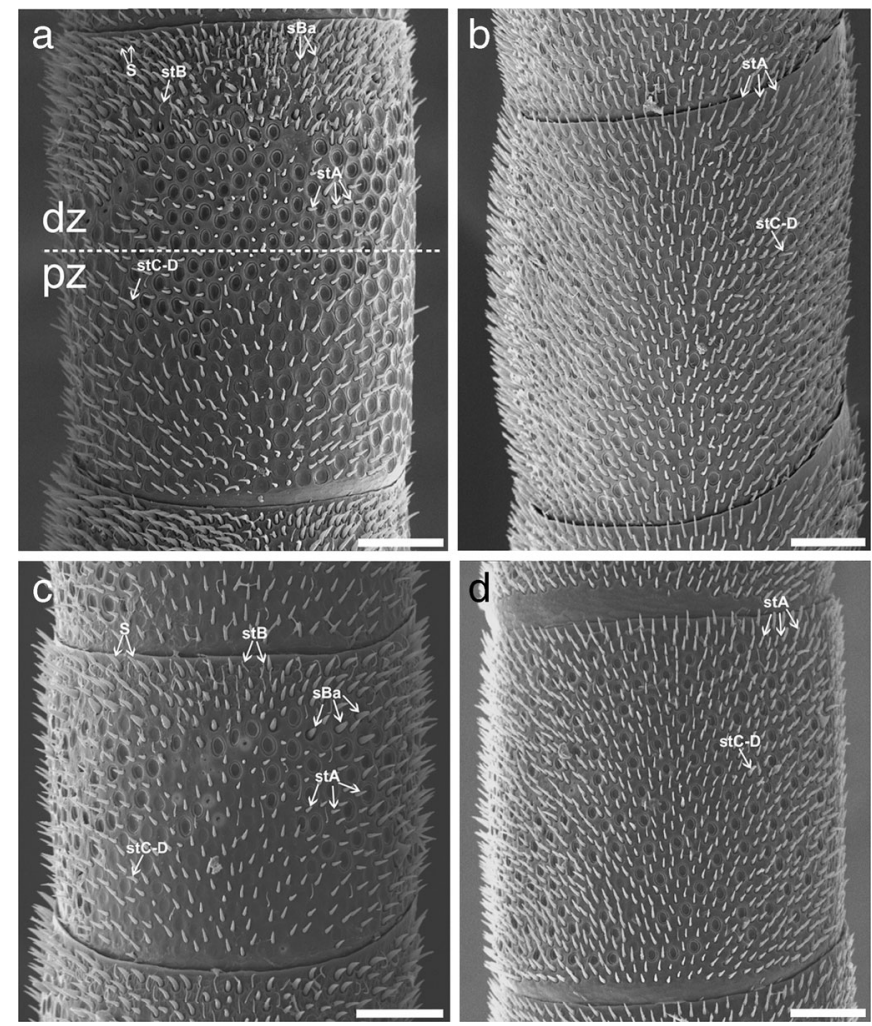

Fig. 1 SEM micrographs of the dorsal surface of F8 in females of Thygater analis (a), Doeringiella nobilis (b), Melitoma segmentaria (c), and Leiopodus lacertinus (d). Dotted line on F8 marks the division between the distal $(d z)$ and the proximal zone $(p z)$ of this flagellomere. Note the differences in length of F8 among the species as well as in the distribution of sensilla placodea. Abbreviations: $s t A$ sensilla trichodea type A, $s t B$ sensilla trichodea type B, $s t C-D$ sensilla trichodea type C-D, $s B a$ sensilla basiconica, and $s$ seta. Bars $=50 \mu \mathrm{m}$.

by cuticle, without any evidence of nerve endings or somata.

\subsubsection{Sensillum trichodeum type A (stA)}

Sensilla trichodea were described as hair-like sensilla (Figure 1a-c and ESM: Figures S1 and $\mathrm{S} 2$ ). In the dorsal surface of the flagellomere, stA are the most abundant and they can be distinguished from the other types of trichodea by its curvature towards the cuticular surface of the flagellomere. Their tips are oriented distally (Figures 1a-c, 3a, and 5a). Differences in length and degree of curvature were detected in the different bee species which can make it difficult to distinguish stA from setae. However, the rounded tips together with the presence of a soft membrane in the hair socket are additional features that aided the right identification (Figure $3 \mathrm{a}$ inset). TEM of stA showed that the cuticle is thin with pores (Figure $3 b$ ). Branching nerve fibers were found at the base (Figure 3b, c). Thus, stA can be considered as multiporous sensilla.

\subsubsection{Sensillum trichodeum type B (stB)}

Within sensilla trichodea, stB is the thinnest (Figure 2a). Most part of the hair is curved towards the cuticular surface (Figures $2 \mathrm{a}$ and $3 \mathrm{a}$ ). Ultrathin sections confirm stB as a nonporous sensillum (Figure $4 a-c)$. Several profiles of nerve fibers were detected at the level of its insertion in the cuticle. 

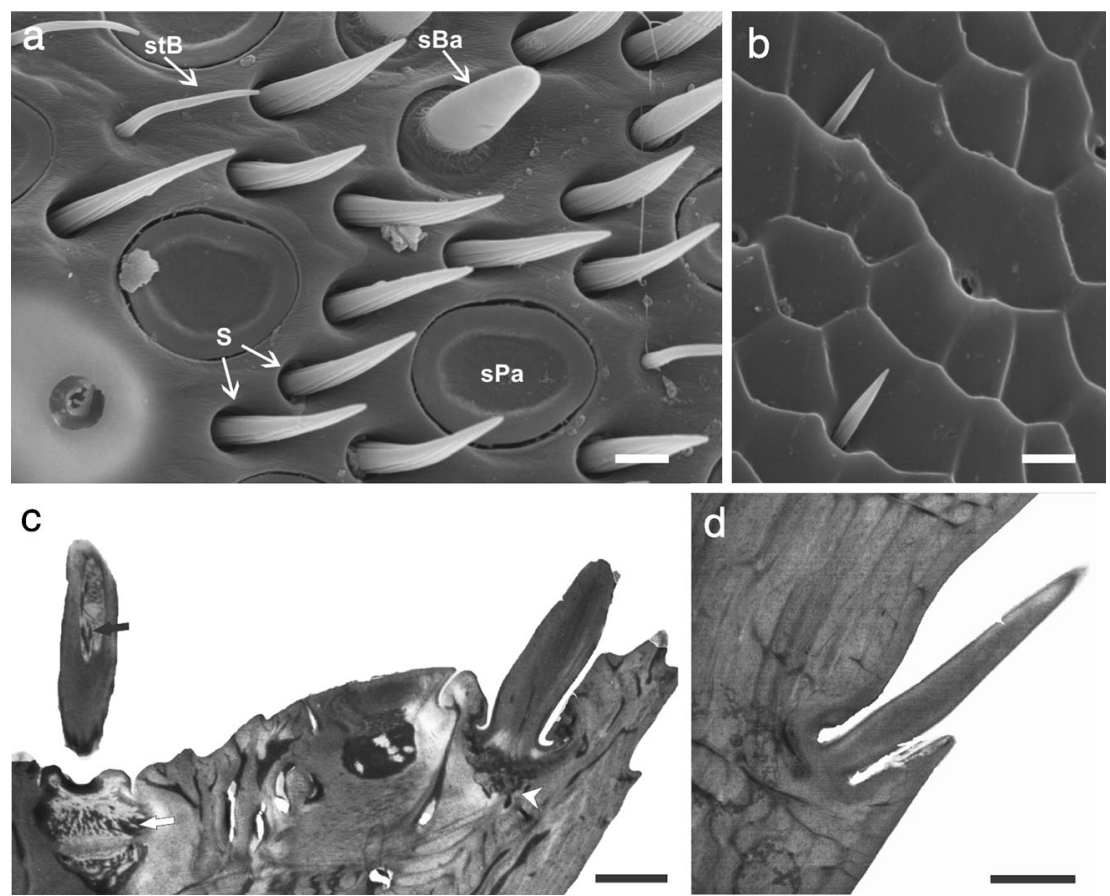

Fig. 2 SEM (a, b ) and TEM (c, d ) micrographs of F10 in Thygater analis, female. a The dorsal surface showing sensilla basiconica and trichodea type B. Setae are present in the dorsal as well as in the ventral surface of the flagellomere as shown in b. c Longitudinal sections of two hairs; white arrow points to neural structures inside the cuticle of the sensilla at the left of the picture, and black arrow marks branches from nerve cells inside the hair. The socket of the right seta is marked by a white arrowhead; note dark fibrous material and absence of nervous tissue. $\mathbf{d}$ Micrograph of a ventral seta showing its insertion in the cuticular surface and the lack of neural structures underneath. Abbreviations: $s t B$ sensillum trichodeum type B, $s B a$ sensillum basiconicum, $s$ seta. Bars in a$\mathbf{c}=4 \mu \mathrm{m}, \mathbf{d}=5 \mu \mathrm{m}$.

\subsubsection{Sensillum trichodeum type $C-D$ (stC-D)}

The stC-D (Figure 5a and ESM: Figure S1) comprises two subtypes: a long one mainly observed on the ventral side of the flagellomere, whereas the shorter form was generally seen on the dorsal surface. Here, we have considered the most abundant subtype which is located on the dorsal side of the flagellomeres. Dorsal stC-D are 10-14 $\mu \mathrm{m}$ long. These sensilla are erect with the tip slightly bent upwards (Figure 5a and ESM: Figure S2). The sockets of stC-D are similar to those found in stA.

Short stC-D resembles sBa except for the fact that its insertion area is smaller and its tip sharper. Both the tip and base of stC-D showed an unbranched outer segment enclosed by a dendritic sheath (Figure $5 b$ ). These data allowed us to consider stC-D as uniporous sensilla (Figure 5b, c).

\subsection{Pattern of antennal sensilla in cleptoparasite-host associations}

\subsubsection{Distribution of sensilla and setae}

In females of $T$. analis and M. segmentaria, the dorsal surface of F6-10 showed two zones which may be defined by the difference in the types of sensilla. The proximal zone is the area housing $\mathrm{sBa}$ and dorsal setae although there is more abundance of stC-D. The distal zone is characterized by abundant stA and $\mathrm{sPa}$ (Figure 1a, c). From F5 to F3, the number of setae increased from the lateral to the dorsal side. Setae are the most abundant hairs in F1-F2. Males of 

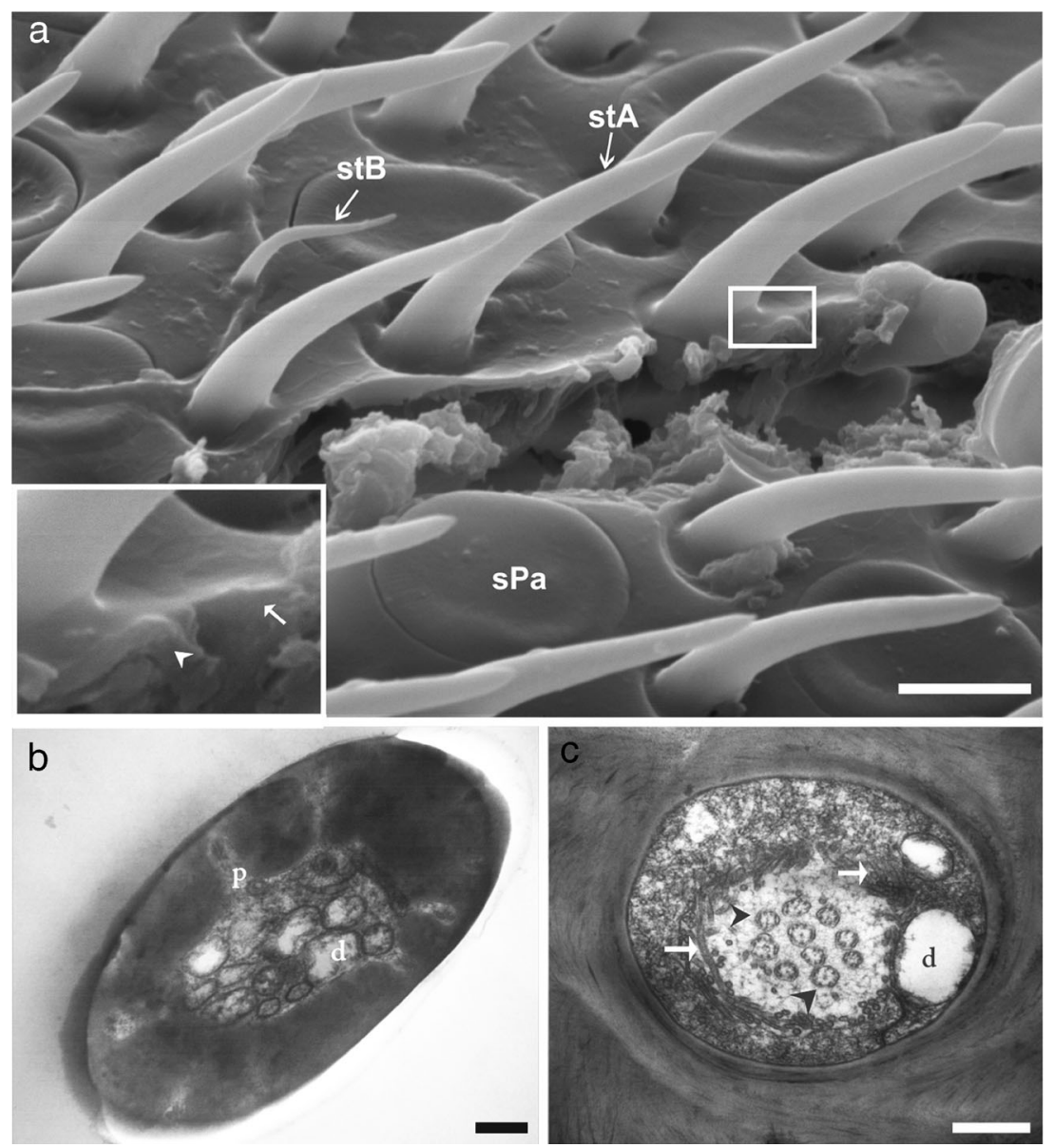

Fig. 3 SEM (a) and TEM (b, c) micrographs of antennal sensilla in Doeringiella nobilis . a F10 housing sensilla trichodea types A (stA), B ( $s t B)$, and placodea $(s P a)$. The inset is a higher magnification of the boxed area at the groove of the cuticle formed during the processing of the tissue. The socket (arrow) and inner tissues of the sensillum (arrowhead) can be distinguished. b Cross section of a sensillum showing pore channels $(p)$ traversing the cuticle. Inside the hair, note dendritic projections $(d)$ of varying widths. $\mathbf{c}$ Transverse section of a sensillum at the level of the ciliary region containing the sensory processes (arrowheads), the distal parts of the dendrites $(d)$, and the projections of the auxiliary cells (arrows). Bars in $\mathbf{a}=5 \mu \mathrm{m}, \mathbf{b}, \mathbf{c}=1 \mu \mathrm{m}$.

M. segmentaria showed a similar pattern of setae to that observed in females. Leiopodus lacertinus and $D$. nobilis showed no difference in the distribution of sensilla in any of the zones (Figure 1b, d). Moreover, dorsal setae were absent in F2-F10/11.

\subsubsection{Density of sensilla types}

In all the species studied here, the highest density of sensilla corresponded to stA, followed by sPa, stB, and stC-D (ESM: Table SIIa, b), the only exceptions being the males of $T$. analis. In this case, the long F2-F11 were mostly covered by sPa, which were twice as much as those of their conspecific females (ESM: Table SIIa). The stA were more abundant in the parasitic species than in their hosts. Host species showed more abundance of stB and stC-D (ESM: Table SIIa, b).

\subsubsection{Abundance of antennal sensilla}

Figure 6 depicts data about the abundance of sensilla respect to their position on the flagella. 

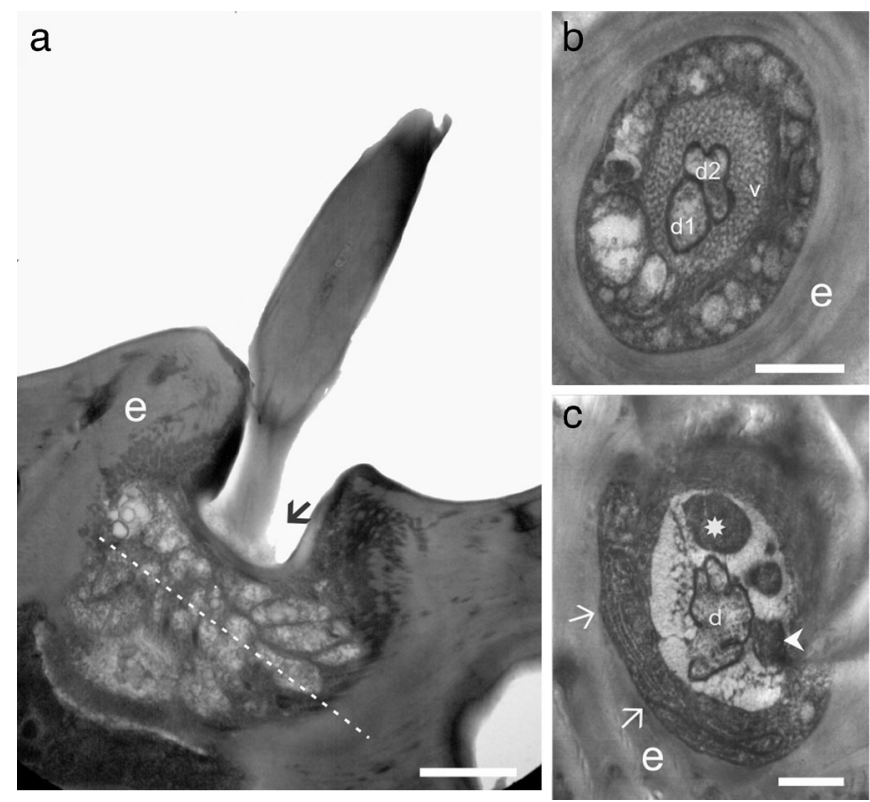

Fig. 4 TEM micrographs of Thygater analis, male antenna. a Dorsal surface of F10. Sensilla trichodea type B, semi-tangential section of the hair, and socket. The cuticle of the hair shaft displays different densities. Inside the epicuticle, note oval structures containing round vesicles. b Cross section at the level of dotted line in picture a. In the center, two dendrites $(d 1$ and $d 2)$ are surrounded by the corresponding dendritic sheaths. Around them, numerous villous projections $(v)$ form a chamber. Between this area and the surface of the cuticle, a rim composed by tubular projections of different diameters. $\mathbf{c}$ Section at a deeper level than that of micrograph $\mathbf{b}$. In the center, dendritic projections $(d)$ wrapped by an electron dense dendritic sheath (arrowhead). A star marks one of the electron dense granules. Arrows point to microlamellae of outer auxiliary cells. e Cuticle. Bars $=1 \mu \mathrm{m}$.

ANOVA revealed significant differences for the three types of sensilla (multi-, uni-, and nonporous) in T. analis and M. segmentaria (Figure 6 and Table I). Females showed more abundance in uni- and nonporous sensilla, while multiporous sensilla were more abundant in males (Table I). Moreover, in females, the post hoc test revealed that the distal flagellomere contains the highest number of uniporous and nonporous sensilla, followed by the medial and the proximal segments $(P<0.05)$. Males of T. analis and M. segmentaria showed no significant difference in terms of the position of these structures on the flagella, except for the multiporous sensilla, which were more abundant on the distal flagellomere in M. segmentaria $(P<0.05$, Table I). In cleptoparasitic species, sexual differences were only observed in the number of multiporous sensilla which were higher in $D$. nobilis females (Table I and Figure 6). In L. lacertinus females, the effect of position was evidenced by more abundant multiporous sensilla in the medial than in the proximal area. Besides, in both sexes, we have detected more uniporous and nonporous sensilla in the distal flagellomeres than in the proximal ones. In $D$. nobilis, only the nonporous sensilla on the proximal flagellomere showed a significantly lower abundance than those of the distal flagellomere $(P<0.05$, Table I).

\subsection{Pattern of antennal sensilla in Apinae and Nomadinae}

The pattern of sensilla between sexes is similar to that described in Section 3.2. Non-parasitic bees showed sexual dimorphism with an elevated number of sBa, stB, and stC-D in the distal flagellomeres of females (Figure 7). On the other hand, cleptoparasitic species showed no sexual difference in the composition of sensilla (Figure 7 and ESM: Figure S2c, d). We have found that all the types of sensilla were present on the dorsal surface of flagella 


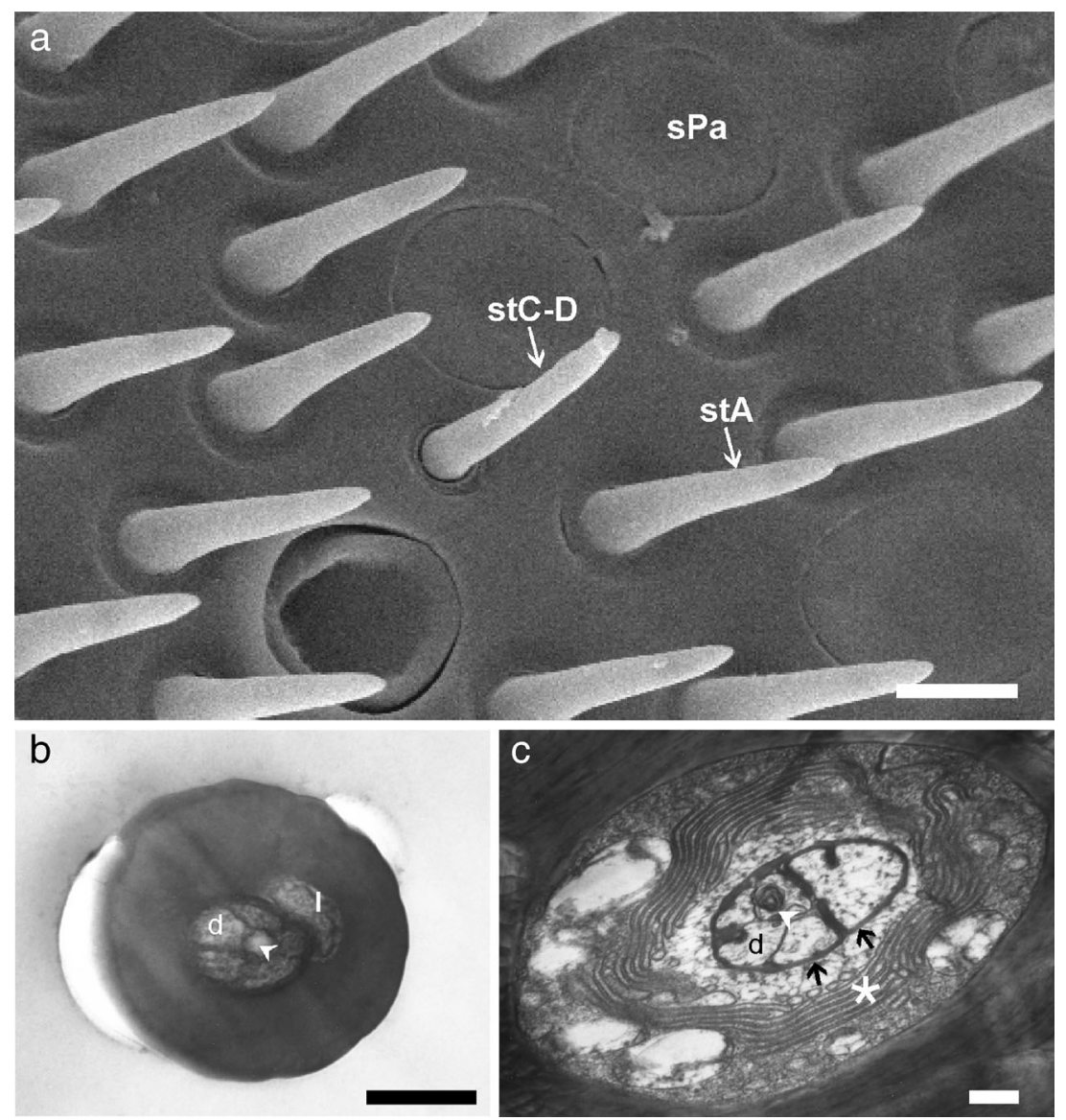

Fig. 5 Leiopodus lacertinus . SEM (a) and TEM (b , c ) micrographs of antennal sensilla. a Sensilla trichodea type A $(s t A)$, type C-D $(s t C-D)$, and placodea $(s P a)$. b Cross section at the distal end of stC-D showing five dendrites $(d)$ filled with vesicles, a central canal (arrowhead), and the sensillum lumen $(l)$. c Cross section showing dendrites $(d)$ enclosed by dendritic sheath (arrows). Arrowhead points to a multilamellar body. Note the microlamellar structure formed by the membranes of auxiliary cells (asterisk). Bars in $\mathbf{a}=1 \mu \mathrm{m}, \mathbf{b}=0.5 \mu \mathrm{m}$.

except for $\mathrm{sBa}$ which were absent in most of the cleptoparasitic species and in all the male specimens. A few short sBa were observed at the tip of flagella of cleptoparasitic females, but the dorsal sBa considered in this study were only observed in the females of Mesoplia rufipes and Isepeolus vachali (ESM: Figure S2i). Analysis by PCA showed the correlation between the type and the position of the antennal sensilla in the flagella of males and females for the taxa listed in ESM: Table SI and Figure 8. The two principal components taken together account for $76.7 \%$ of the total variation, and a plot of these factors showed a cluster of non-parasitic females in negative coordinates of PC I, whereas a cluster of males of non-parasitic and both sexes of cleptoparasitic bees is set in positive values of the same axis (Figure 8). The positive values of the first component were highly correlated with multiporous sensilla, whereas the coordinates corresponding to negative values were defined by uniporous and nonporous sensilla and to a lesser extent to setae (ESM: Table SIII). The PC II and PC III showed the low correlation of setae with the different types of sensilla (ESM: Table SIII).

\section{DISCUSSION}

In this paper, we have characterized the morphology of antennal sensilla in numerous solitary and cleptoparasitic species of Apidae. Until now, 

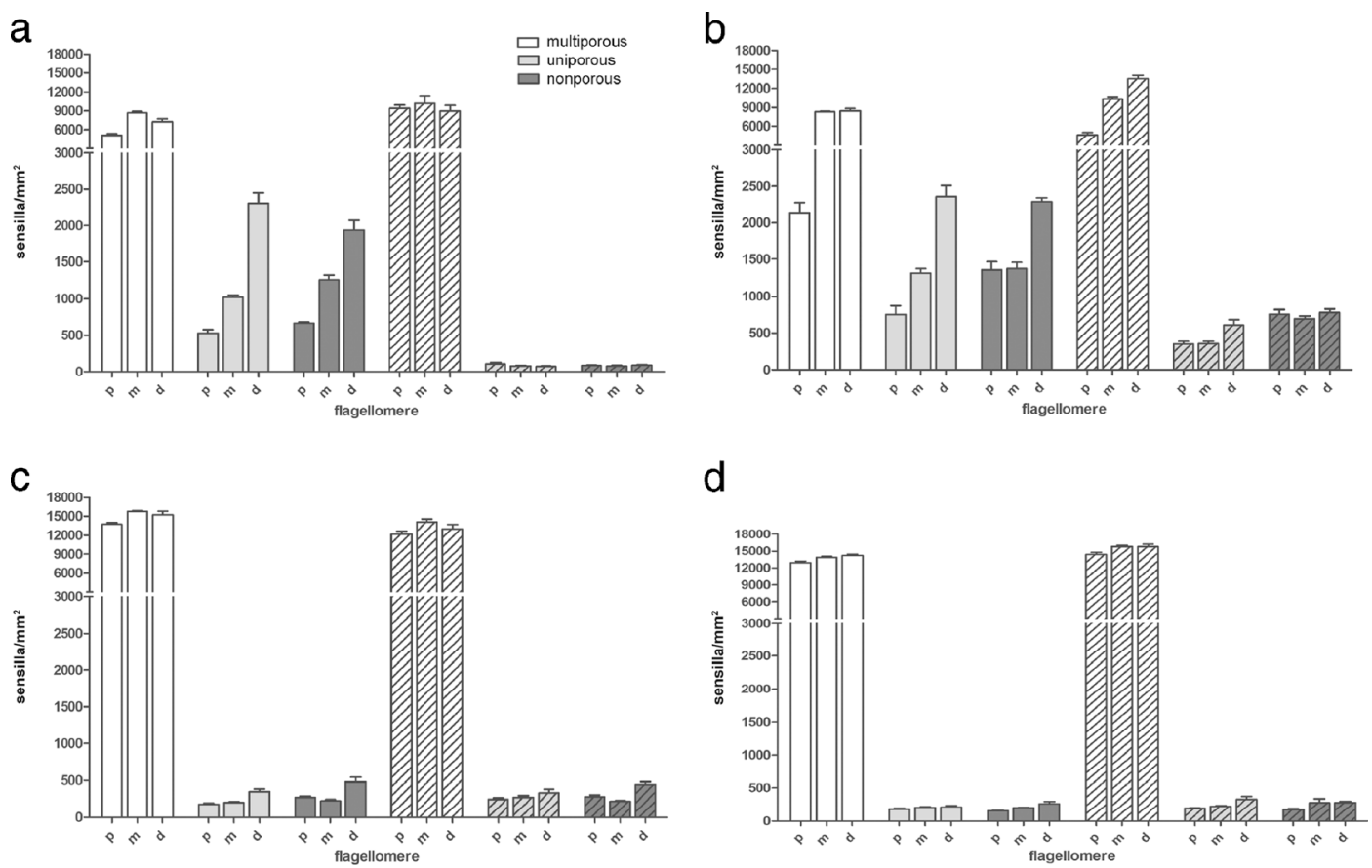

Fig. 6 Densities of different classes of sensillum types according to location in the proximal $(p)$, medial $(m)$, and distal $(d)$ section of the flagella. Values at the left (shaded columns) of each graph correspond to female insects, whereas those at the right represent males (striped columns). a Thygater analis, b Melitoma segmentaria, c Leiopodus lacertinus, and d Doeringiella nobilis. Error bars correspond to the standard error of the mean $(n=8)$. Note the low values of uni- and nonporous sensilla in cleptoparasitic females, which are similar to their conspecific males.

ultrastructural descriptions have been performed only in corbiculate bees (Slifer and Sekhon 1961; Whitehead and Larsen 1976). Our ultrastructural studies with species of Eucerini, Emphorini,
Epeolini, and Protepeolini confirmed that stA belong to the multiporous type, whereas stC-D are uniporous and stB are nonporous. This approach allowed us to assign putative functions to each

Table I. Values of Fischer ratios obtained by ANOVA with sex $\left(F_{1,42}\right)$ and position in the flagellum $\left(F_{2,42}\right)$ as subject factors for the three different classes of sensillum types in cleptoparasitic and host species

\begin{tabular}{lllll}
\hline & & Multiporous & Uniporous & Nonporous \\
\hline Thygater analis & Sex & $20.1^{*}$ & $545.7^{* *}$ & $549.7^{* *}$ \\
& Flag & 5 & $104.1^{* *}$ & $51.6^{* *}$ \\
Melitoma segmentaria & Sex & $122.2^{* *}$ & $209.1^{* *}$ & $284.7^{*}$ \\
& Flag & $254.3^{* *}$ & $58.3^{* *}$ & $35^{*}$ \\
Doeringiella nobilis & Sex & $23.01^{*}$ & 5.2 & 1.43 \\
& Flag & 5.9 & 5.9 & $15.52^{*}$ \\
Leipodus lacertinus & Sex & $22.3^{*}$ & 2.8 & 0.1 \\
& Flag & 9.1 & $10.8^{*}$ & $27.2^{*}$ \\
\hline
\end{tabular}

$* P<0.001$, significant values for main effects; $* * P<0.001$, significant values for interaction effects 


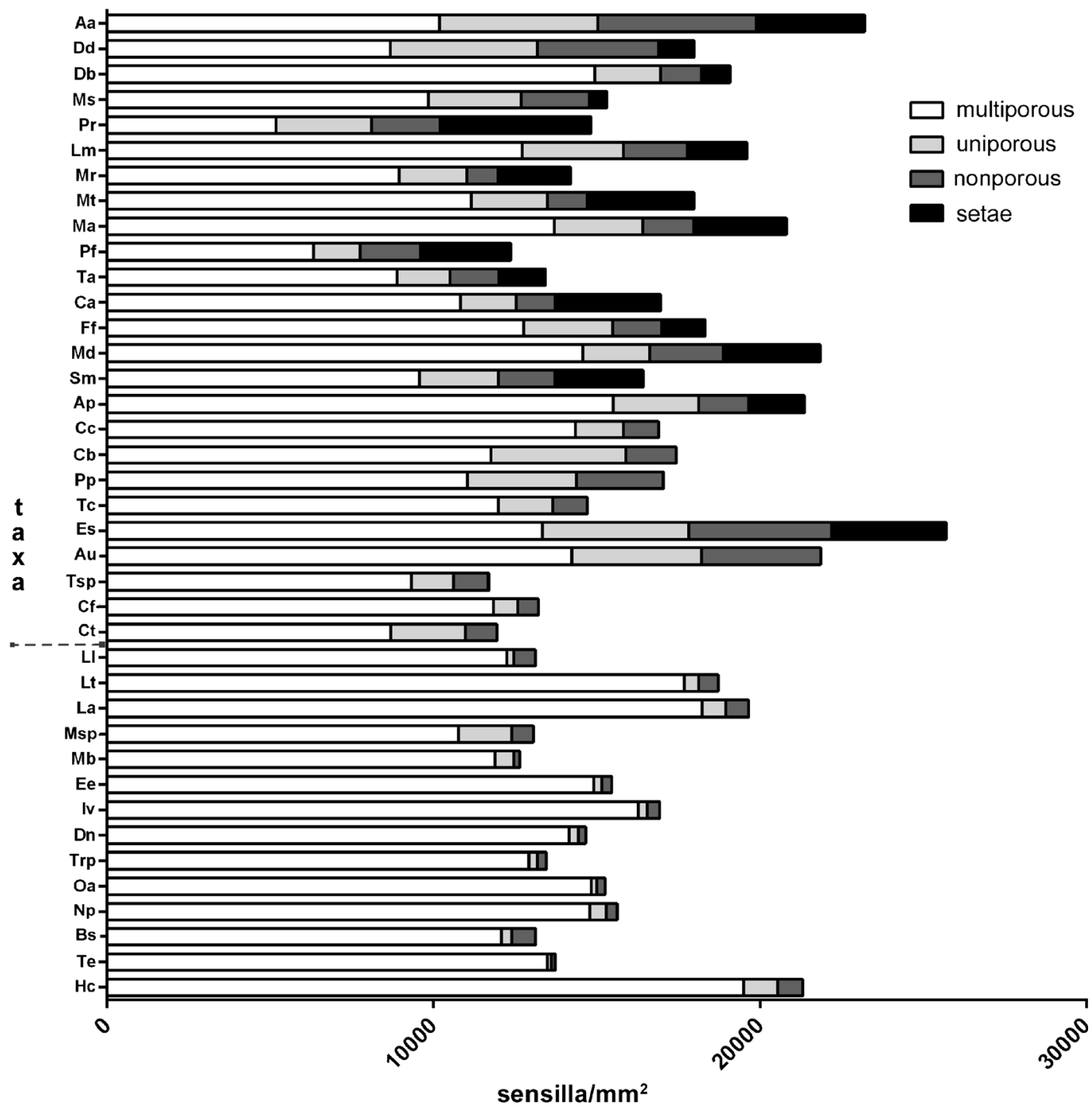

Fig. 7 Densities in multiporous, uniporous and nonporous sensilla on F10 of females of Apidae. Columns represent the proportion of each type of sensillum with respect to the total density. Dotted line separates non-parasitic (above) from cleptoparasitic species (below). Abbreviations of the species names can be found in ESM: Table SI.

type of sensilla and provided additional criteria to perform more accurate comparisons than those based solely on SEM observations of the external morphology. Nervous tissue was absent in both types of setae, a fact which is in agreement with previous reports for a non-sensory function of these structures (Eichmüller and Schäfer 1995; Ågren and Hallberg 1996).

The main difference in the patterns of sensilla among the species corresponded to the presence of $\mathrm{sBa}$ and setae. In non-parasitic females, both antennal structures are always present in the dorsal surface of flagellomeres allowing the description of two zones: distal and proximal. Eucerini and Emphorini species showed conspicuous rows of dorsal setae in the distal zone. The segregation in the dorsal distribution of sensilla was already observed in bees of Colletidae, Andrenidae, Halictidae, and Apidae (Ågren 1977, 1978; Ågren and Svensson, 1982; Galvani et al. 2012; 


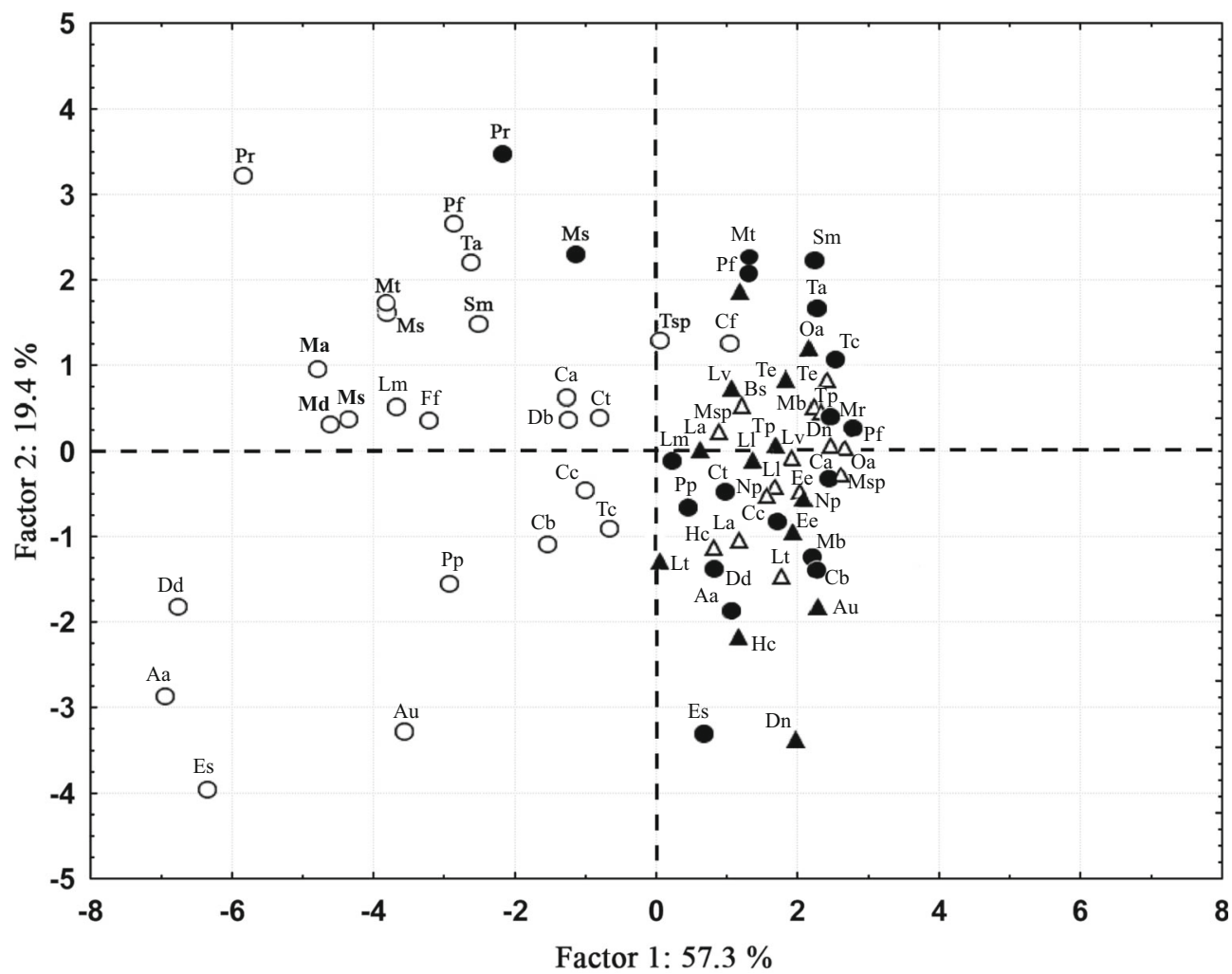

Fig. 8 Plots of sample scores extracted by the principal components I and II. Non-parasitic bees are represented by circles and cleptoparasitic specimens by triangles. Females are white symbols and males are black symbols. Note that parasitic females are restricted to the right quadrant within parasitic and non-parasitic males.

Streinzer et al. 2013). On the contrary, in cleptoparasitic species, such a difference in the distribution of sensilla is very low or nonexistent. Moreover, most of the cleptoparasitic specimens of this study lacked setae in the dorsal area and showed high numbers of stA and sPa, which displayed uniform distributions.

The absence of $\mathrm{sBa}$ in cleptoparasitic females of Nomadinae is remarkable. The presence of $\mathrm{sBa}$ was reported in females of solitary species and workers of social bees (Esslen and Kaissling 1976; Galvani et al. 2012; Ravaiano et al. 2014). However in Halictidae, non-parasitic species of the genus Corynura lack sBa (González-Vaquero and Galvani 2016), whereas they were observed in the parasitic genus Sphecodes (Ågren and Svensson, 1982). In our studies, only cleptoparasitic species of Osirini and Ericrocidini showed sBa in the dorsal surface of flagellomeres.
In these sense, using molecular and behavioral approaches, a pathway for the evolution of cleptoparasitism in Apidae has been proposed (Litman et al. 2013). The absence of sBa in Nomadinae and its presence in certain groups of Apinae are coincident with the brood parasitic lineages proposed by these authors.

Studies on the inventory of sensilla and their correlation with specific behavioral patterns were mainly focused on sexual differences. Our results support the hypothesis that non-parasitic species having sexual dimorphisms present differences in the abundance of multiporous sensilla (Esslen and Kaissling 1976; Ågren 1977, 1978; Galvani et al. 2012; Streinzer et al. 2013; Ravaiano et al. 2014). The sensory system of male bees shows a wide variety of adaptations for the olfactory perception of signals from conspecific females (Wcislo 1995; Brockmann and Brückner 2001; Roselino et al. 
2015). In our study, the number of sPa was always higher in males, but in most of the species, the differences between males and females were lower than those reported for A. mellifera (Brockmann \& Brückner 2001) and eucerines (Streinzer et al. 2013). However, males also possessed a high number of stA. In conclusion, all non-cleptoparasitic males showed a higher abundance of multiporous sensilla than females. On the contrary, uniporous (stC-D and sBa) and nonporous (stB) sensilla were more abundant in nonparasitic females than in conspecific males. Furthermore, in non-parasitic females, these types of sensilla appeared to be concentrated in the distal flagellomeres.

A higher number of multiporous and a lower number of uni- and nonporous sensilla were observed in cleptoparasitic females in respect to nonparasitic ones. These findings suggest that cleptoparasitic females have a less diverse equipment of sensilla, with a predominance of olfactory structures. In this regard, it was reported that cleptoparasitic Epeoloides coecutiens has the ability to detect odors from either the host species or the corresponding host plants (Dötterl 2008). Studies in species of Nomada revealed that during the invasion of the host nest, the antenna is employed as a scanner by coming into contact with the surface of the substrate (Cane 1983). As stA can act as both olfactory and mechanoreceptor organs, it is possible that its abundance in parasitic females might be related to the detection of host nests.

A study involving 114 species of Apidae revealed that the conspicuous sexual dimorphism in the length of the antennal flagella is absent in the parasitic taxa (Wcislo 1995). We did not detect sexual dimorphism in the sensilla of cleptoparasitic bees. Cleptoparasitic females may use visual and long- or mid-range chemical cues for the detection of the host nest, cues that might resemble those employed by males in the search for the conspecific partner (Wcislo 1995). Our results provide additional support to the hypothesis of masculinization of the antennal morphology in cleptoparasitic bees. Further studies on the distribution of sensilla and their functionality may contribute to a better understanding of the evolution of cleptoparasitism in bees.

\section{ACKNOWLEDGEMENTS}

The authors thank Dr. A.H. Roig-Alsina for providing access to the collection of the MACN and helpful discussions. Thanks are also due to Fabián Tricárico for technical assistance. BPS and GLG are members of the CIC-CONICET. RAGV is a postdoctoral fellow of CONICET. The study was supported by T00-2013, Universidad Austral (BPS).

Contributions GLG conceived the study, performed the experiments, and wrote the paper. RGV performed research. CGN performed statistical analysis. BPS discussed results, wrote the paper, and conducted the research.

Sensilles antennaires d'abeilles cleptoparasites et d'abeilles non-parasites chez deux sous-familles d'Apidae

Antenne / morphologie / ultrastructure des sensilles / olfaction / dimorphisme

Antennale Sensillen kleptoparasitischer und nichtparasitischer Bienen aus zwei Unterfamilien der Apidae

Antennenmorphologie / Sensillenultrastruktur / Geruchssinn / Dimorphismus

\section{REFERENCES}

Ågren, L. (1977) Flagellar sensilla of some colletidae (Hymenoptera: Apoidea). Int. J. Insect Morphol Embryol. 6, $137-146$

Ågren, L. (1978) Flagellar sensilla of two species of Andrena (Hymenoptera: Andrenidae). Int. J. Insect Morphol Embryol. 7, 73-79

Ågren, L., Hallberg, E. (1996) Flagellar sensilla of bumble bee males (Hymenopera, Apidae, Bombus). Apidologie 25, 433-444

Ågren, L., Svensson, B.G. (1982) Flagellar sensilla of Sphecodes bees (Hymenoptera, Halictidae). Zool. Scri. 11, 45-54

Aguirre, S.A., Pons, P., Settembrini, B.P., Arroyo, D., Canavoso, L.E. (2013) Cell death mechanisms during follicular atresia in Dipetalogaster maxima, a vector of Chagas' disease (Hemiptera: Reduviidae). J. Insect Physiol. 59, 532-541

Brockmann, A., Brückner, D. (2001) Structural differences in the drone olfactory system of two phylogenetically distant Apis species, A. florea and A. mellifera. Naturwissenschaften $\mathbf{8 8}, 78-81$ 
Cane, J.H. (1983) Olfactory evaluation of Andrena host nest suitability by kleptoparasitic Nomada bees (Hymenoptera: Apoidea). Anim. Behav. 31 , 138-144

Chapman, R.F. (1982) Chemoreception: The significance of receptor numbers. Adv. Insect Physiol. 16, 247-356

Dötterl, S. (2008) Antennal responses of an oligolectic bee and its cleptoparasite to plant volatiles. Plant Signal. Behav. 3 , 296-297

Eichmüller, S., Schäfer, S. (1995) Sensory neuron development revealed by taurine immunocytochemistry in the honey bee. J. Comp. Neurol. 352, 297-307

Esslen, J., Kaissling, K.E. (1976) Zahl und Verteilung antennaler Sensillen bei der Honigbiene (Apis mellifera L.). Zoomorphologie 83, 227-251

Galvani, G.L., Settembrini, B.P., Roig-Alsina, A.H. (2008) Morphology of antennal sensilla in Doeringiella nobilis (Hymenoptera: Apidae). J. Kansas Entomol. Soc. 81, 142-152

Galvani, G.L., González, A., Roig-Alsina, A.H., Settembrini, B.P. (2012) Distribution and morphometric studies of flagellar sensilla in Emphorini bees (Hymenoptera, Apoidea). Micron 43, 673-87

González-Vaquero, R.A., Galvani, G.L. (2016) Antennal sensilla analyses as useful tools in the revision of the sweat-bee subgenus Corynura (Callistochlora) Michener (Hymenoptera: Halictidae). Zool. Anz. 262 , 29-42

Litman, J.R., Praz, C.J., Danforth, B.N., Griswold, T.L., Cardinal, S. (2013) Origins, evolution, and diversification of cleptoparasitic lineages in long-tongued bees. Evolution. 67, 2982-2998

Michener, C. (2007) The Bees the World, 2nd The Johns Hopkins University Press, Baltimore

Mysore, K. Shyamala, B.V., Rodrigues, V. (2010) Morphological and developmental analysis of peripheral antennal chemosensory sensilla and central olfactory glomeruli in worker castes of Camponotus compressus (Fabricius, 1787). Arthropod Struct Dev. 39, 310-21

Ozaki, M., Wada-Katsumata, A., Fujikawa, K., Iwasaki, M., Yokohari, F., Satoji, Y., et al. (2005) Ant nestmate and non-nestmate discrimination by a chemosensory sensillum. Science 309, 311-314

Polidori, C., García, A.J., Nieves-Aldrey, J.L. (2012) Antennal sensillar equipment in closely related predatory wasp species (Hymenoptera: Philanthinae) hunting for different prey types. C. R. Biol. 335 , 279-291

Ravaiano, S.V., Ferreira, R.D.P., Campos, L.A., Martins, G.F. (2014) The antennal sensilla of Melipona quadrifasciata (Hymenoptera: Apidae: Meliponini): A study of different sexes and castes. Naturwissenschaften 101, 603-611

Riveros, A.J., Gronenberg, W. (2010) Sensory allometry, foraging task specialization and resource exploitation in honeybees. Behav. Ecol. Sociobiol. 64, 955-966

Roselino, A.C., Hrncir, M., da Cruz Landim, C., Giurfa, M., Sandoz, J.C. (2015) Sexual dimorphism and phenotypic plasticity in the antennal lobe of a stingless bee, Melipona scutellaris. J. Comp. Neurol. 523, 1461-1473

Sandoz, J.C., Deisig, N., de Brito Sanchez, M.G., Giurfa, M. (2007) Understanding the logics of pheromone processing in the honeybee brain: from labeled-lines to across-fiber patterns. Front. Behav. Neurosci. 1, 5

Sheridan, S.L. (1996) The role of chemical senses in seedcarrying behavior by ants: A behavioral, physiological and morphological study. J. Insect Physiol. 42, 149159

Slifer, E.H., Sekhon, S.S. (1961) Fine structure of the sense organs on the antennal flagellum of the honey bee, Apis Mellifera Linnaeus. J. Morphol. 109, 351-358

Spaethe, J., Brockmann, A., Halbig, C., Tautz, J. (2007) Size determines antennal sensitivity and behavioral threshold to odors in bumblebee workers. Naturwissenschaften 94, 733-739

Streinzer, M., Kelber, C., Pfabigan, S., Kleineidam, C.J., Spaethe, J. (2013) Sexual dimorphism in the olfactory system of a solitary and a eusocial bee species. J. Comp. Neurol. 521 , 2742-2755

Wcislo, W.T. (1995) Sensilla numbers and antennal morphology of parasitic and non-parasitic bees (Hymenoptera: Apoidea). Int. J. Insect Morphol. Embryol. 24, 63-81

Whitehead, A.T., Larsen, J.R. (1976) Ultrastructure of the contact chemoreceptors of Apis mellifera L. (Hymenoptera: Apidae). Int. J. Insect Morphol. Embryol. 5, 301-315 